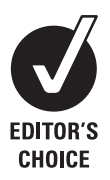

${ }^{1}$ Cardiorenal Research Laboratory, Mayo Clinic, Rochester, Minnesota, USA; ${ }^{2}$ Division of Cardiovascular Diseases, Mayo Clinic, Rochester, Minnesota, USA; ${ }^{3}$ Department of Emergency Medicine, Mayo Clinic, Rochester, Minnesota, USA

Correspondence to: Dr H H Chen, Cardiorenal Research Laboratory, Mayo Clinic, 200 First Street SW, Rochester, MN 55904, USA chen.horng@mayo.edu

Accepted 24 February 2009 Published Online First 15 May 2009

\title{
Low-dose nesiritide in human anterior myocardial infarction suppresses aldosterone and preserves ventricular function and structure: a proof of concept study
}

\author{
H H Chen, ${ }^{1,2}$ F L Martin, ${ }^{1,2}$ R J Gibbons, ${ }^{2}$ J A Schirger, ${ }^{1,2}$ R S Wright, ${ }^{2}$ R M Schears, ${ }^{3}$ \\ M M Redfield, ${ }^{1,2}$ R D Simari, ${ }^{2}$ A Lerman, ${ }^{2}$ A Cataliotti, ${ }^{1}, 2$ J C Burnett Jr ${ }^{1,2}$
}

\begin{abstract}
Background: B-type natriuretic peptide (BNP, nesiritide) has anti-fibrotic, anti-hypertrophic, anti-inflammatory, vasodilating, lusitropic and aldosterone-inhibiting properties but conventional doses of BNP cause hypotension, limiting its use in heart failure.

Objective: To determine whether infusion of low-dose BNP within $24 \mathrm{~h}$ of successful reperfusion for anterior acute myocardial infarction (AMI) would prevent adverse left ventricular (LV) remodelling and suppress aldosterone. Methods: A translational proof-of-concept study was carried out to determine tolerability and biological activity of intravenous BNP at 0.003 and $0.006 \mu \mathrm{g} / \mathrm{kg} / \mathrm{min}$, without bolus started within $24 \mathrm{~h}$ of successful reperfusion for anterior AMI. 24 patients with first anterior wall ST elevation AMI and successful revascularisation were randomly assigned to receive $0.003(\mathrm{n}=12)$ or 0.006 ( $\mathrm{n}=12$ ) $\mu \mathrm{g} / \mathrm{kg} / \mathrm{min}$ of IV BNP for $72 \mathrm{~h}$ in addition to standard care during hospitalisation for anterior AMI.
\end{abstract}

Results: Baseline characteristics, drugs and peak cardiac biomarkers for myocardial damage were similar between both groups. Infusion of BNP at $0.006 \mu \mathrm{g} / \mathrm{kg} / \mathrm{min}$ resulted in greater biological activity than infusion at $0.003 \mu \mathrm{g} / \mathrm{kg} /$ min as measured by higher mean (SEM) plasma cGMP levels (8.6 (1) vs 5.5 (1) pmol/ml, p<0.05) and suppression of plasma aldosterone (8.0 (2) to 4.6 (1) ng/ $\mathrm{dl}, \mathrm{p}<0.05)$, which was not seen in the $0.003 \mu \mathrm{g} / \mathrm{kg} / \mathrm{min}$ group. LV ejection fraction (LVEF) improved significantly from baseline to 1 month (40 (4)\% to $54(5) \%, p<0.05)$ in the 0.006 group but not in the 0.003 group. Infusion of BNP at $0.006 \mu \mathrm{g} / \mathrm{kg} / \mathrm{min}$ was associated with a decrease of LV end-systolic volume index (61 (9) to 43 (8) $\mathrm{ml} / \mathrm{m}^{2}$, $p<0.05)$ at 1 month, which was not seen in the 0.003 group. No drug-related serious adverse events occurred in either group.

Conclusions: $72 \mathrm{~h}$ infusion of low BNP at the time of anterior AMI is well tolerated and biologically active. Patients treated with low-dose BNP had improved LVEF and smaller LV end-systolic volume at 1 month.

Acute myocardial infarction (AMI) is a complication of coronary artery disease and results in loss of ventricular myocardium with cardiac enlargement and fibrosis that may evolve to heart failure (HF). Ongoing research into the role of the heart as an endocrine organ has provided insight into the biology of the cardiac natriuretic peptide, B-type natriuretic peptide (BNP), which as a small endogenous hormone possesses properties that may protect the heart from injury as well as inhibit unfavourable remodelling after injury. Studies have shown that BNP binds to the NPRA particulate guanylyl cyclase receptor and elevates cyclic 3', 5'-guanosine monophosphate (cGMP). Cyclic GMP leading to activation of cGMPdependent protein kinase may result in coronary vasodilatation with a reduction in myocardial oxygen consumption, ${ }^{2}$ enhancement of myocardial relaxation, ${ }^{3}$ retardation of adrenergic activation, ${ }^{4}$ induction of vascular regeneration ${ }^{5}$ and inhibition of cardiac fibroblast collagen synthesis and proliferation, with suppression of cardiomyocyte growth. ${ }^{67}$ Recent studies have also established direct anti-apoptotic actions of the natriuretic peptide system in cardiomyocytes through nuclear accumulation of Akt kinase and zyxin. ${ }^{8}$ Finally, in AMI the critical role of aldosterone continues to emerge based upon its pro-fibrotic properties, renal sodium-retaining actions and role in mediating oxidative stress. Indeed, the level of aldosterone at the time of hospitalisation for AMI is a robust predictor of poor outcome. Importantly, both atrial natriuretic peptide (ANP) and BNP suppress synthesis and release of aldosterone and therefore have clear therapeutic relevance to their use in AMI. In 2001, the FDA approved human BNP (nesiritide) for the management of acute decompensated HF.

Recently, the results of a large multicentre clinical trial using ANP at the time of myocardial reperfusion with AMI was reported. ${ }^{9}$ This study reported that ANP (carparitide) reduced infarct size, improved ejection fraction and decreased the rate of new-onset HF. A common adverse effect, however, was hypotension with ANP thought to be secondary to its potent arterial vasodilating properties. Hillock and coworkers recently reported findings of a small study defining the neurohumoral, renal and myocardial responses to $60 \mathrm{~h}$ of BNP infusion in human AMI with delayed or failed reperfusion and moderate left ventricular dysfunction. ${ }^{10}$ This key study demonstrated that BNP used at conventional clinical doses was safe with trends towards favourable ventricular remodelling.

Increasing evidence suggests that the use of lowdose BNP (nesiritide) that avoids hypotension in humans with cardiorenal disease has beneficial properties. La Rocca et al reported that in humans with HF, low-dose BNP suppressed adrenergic outflow in the absence of hypotension. ${ }^{4}$ Recently, we reported that low-dose BNP administered 
perioperatively in patients undergoing cardiac bypass surgery with renal insufficiency compared with placebo resulted in renal protection and suppression of aldosterone. ${ }^{112}$ Of note, low-dose ANP in human AMI also suppressed aldosterone and was associated with improved ventricular function. ${ }^{13}$

Here our goal was to pursue a proof-of-concept study defining in humans with anterior AMI and successful reperfusion if recombinant BNP (nesiritide) would be safely tolerated at low non-hypotensive concentrations together with standard treatment including angiotensin converting enzyme inhibitors and $\beta$ adrenergic antagonists. ${ }^{14}$ We also sought to define the acute responses of cGMP and aldosterone to a $72 \mathrm{~h}$ infusion of BNP, recognising the key role of aldosterone in cardiac remodelling in AMI. We also sought to define the response of left ventricular ejection fraction (LVEF) at 1 month after the $72 \mathrm{~h}$ infusion of $\mathrm{BNP}$ at two doses employed. This proof-of-concept study demonstrated cGMP-activating and aldosterone-suppressing actions together with enhanced LVEF without safety concerns. Thus, this highly translational human study was the rationale for a larger placebo-controlled, double-blind, NIH-supported trial (BELIEVE II) now underway advancing the concept that low-dose nesiritide may mediate preservation of myocardial structure and function in first-time anterior AMI after successful reperfusion.

\section{METHODS}

This was a human physiological study employing two low doses of recombinant BNP (nesiritide, Scios, Fremont, California, USA) at 0.003 (group I) and $0.006 \mu \mathrm{g} / \mathrm{kg} / \mathrm{min}$ (group II), started within $24 \mathrm{~h}$ of reperfusion for anterior AMI. These doses were chosen based upon studies in human HF carried out to determine the ability of BNP at subclinical doses to suppress adrenergic tone. ${ }^{4}$ Thus, our study used two subclinical doses. in part designed to assess the effects of the lowest effective dose of this cardiac peptide in this pilot proof-of-concept human protocol without a placebo control. Note that the clinical dose for BNP for human HF is a $2 \mu \mathrm{g} / \mathrm{kg}$ bolus followed by $0.01 \mu \mathrm{g} / \mathrm{kg} / \mathrm{min}$ intravenously. A total of 24 patients (12 in each group) were randomly assigned to receive either 0.003 or $0.006 \mu \mathrm{g} / \mathrm{kg} / \mathrm{min}$ of intravenous (IV) BNP. The Mayo Clinic Institutional Review Board approved the protocol and all patients gave written consent.

The study group included patients admitted to Mayo Clinic's St Mary's Hospital, Rochester, Minnesota, USA, with a first anterior AMI as diagnosed by the following criteria: prolonged chest pain $>30 \mathrm{~min}$; ST-segment elevation $2 \mathrm{mV}$ in two or more adjacent anterior precordial leads; positive troponin or creatine kinase (CK)-MB; successful reperfusion therapy (TIMI grade 3 flow) within 24 h of onset of chest pain documented by coronary angiography and no previous history of AMI or previous ECG suggesting old AMI. Exclusion criteria were as follows: cardiogenic shock or hypotension; systolic blood pressure $<90 \mathrm{~mm} \mathrm{Hg}$ or overt chronic HF; previous history of myocardial infarction (MI); previous ECG suggesting a previous MI; previously known decreased EF; atrial fibrillation; previously known significant valvular disease (grade III/IV), hypertrophic cardiomyopathy and congenital heart disease; signs and symptoms of post-MI ischaemia during the hospitalisation period; significant restenosis of culprit vessel during the 4 weeks' follow-up period; inability to tolerate any angiotensin converting enzyme inhibitor (ACEI) and haemoglobin <11.6 g/ $\mathrm{dl}$ for female or $<12.4 \mathrm{~g} / \mathrm{dl}$ for male subjects.

In addition to standard medical treatment as determined by the doctor, the ACEI, lisinopril, was started between 12 and $24 \mathrm{~h}$ after the start of IV BNP at an initial dose of $2.5 \mathrm{mg}$ and thereafter titrated up by the participant's doctor according to the patient's clinical status. Blood for measurement of BNP, cGMP and aldosterone was drawn before the initiation of IV $\mathrm{BNP}$ and between 3 and $6 \mathrm{~h}$ into the infusion before the initiation of ACEI. Gated equilibrium radionuclide ventriculography was performed within $24 \mathrm{~h}$ after the initiation of the IV BNP to assess systolic and diastolic volumes and LVEF. All patients, whether they completed the entire $72 \mathrm{~h}$ of the BNP infusion or not, returned 1 month later for repeat gated equilibrium radionuclide ventriculography.

\section{Assessment of ventricular function and structure by gated equilibrium radionuclide ventriculography}

Gated equilibrium radionuclide ventriculography was performed at rest using previously reported techniques and modified in vivo red cell labelling with $30 \mathrm{mCi}$ of technetium$99 \mathrm{~m}$. Anterior, left lateral and left anterior oblique projections were obtained. Data acquisition was gated to the $\mathrm{R}$ wave on the electrocardiogram. LVEF and LV volumes were determined from the background-corrected LV counts versus time curves, a count-based method adjusted for body surface area and an operator-interactive programme using previously published methods. ${ }^{15}$ In summary, LVEF was measured using LV activity independent of volumes. LV volumes were based on the LV enddiastolic activity and LV end-systolic activity but since LV activity is proportional to volume, corrections had to be made to generate volumes. Hence, we measured the activity in a blood sample obtained from the patient and subsequently, related activity in the left ventricle to activity in the blood sample. Blood $(10 \mathrm{ml})$ was taken from the patient after isotope equilibration and the activity in this sample was determined using a gamma camera by a standard method. The LV activity was then corrected (normalised) using the blood sample activity. This normalised LV activity was used to generate LV volumes (systolic or diastolic) using a regression equation (this was generated in comparison with LV angiography). The cardiologists interpreting the studies were blinded to treatment.

One patient in the 0.003 group and two patients in the 0.006 group did not have paired LVEF measurements to allow for comparison. Two patients in the 0.003 group and three patients in the 0.006 group did not have paired LV volumes measurements for comparison. Specifically, in the 0.003 group, one patient decided to withdraw from the study after $12 \mathrm{~h}$ for personal reasons and one patient had only LVEF measured without LV volumes because the technician forgot to draw $10 \mathrm{ml}$ of blood from the patient after isotope equilibration to determine the activity in the blood. In the 0.006 group, one patient who received thrombolytic agents had re-occlusion of the left anterior descending artery before the 4-week follow-up visit; one patient had only LVEF measured without LV volumes because the technician forgot to draw $10 \mathrm{ml}$ of blood from the patient after isotope equilibration to determine the activity in the blood; and one patient in the 0.006 group did not want to return for the follow-up visit.

\section{Neurohumoral measurements}

After extraction, plasma BNP was measured by radioimmunoassay, as previously described. ${ }^{16}$ Radioimmunoassay using the method of Steiner et al measured plasma samples for cGMP and Haber et al for aldosterone. ${ }^{16}$

\section{Statistical analysis}

Results are expressed as mean (SEM). Comparisons between the 0.003 group and the 0.006 group were performed for categorical 
variables using the $\chi^{2}$ test for independence. Analysis of covariance was used to evaluate the difference between the groups adjusting for the baseline measurements of those same factors (ANCOVA). The changes in the number of continuous factors from baseline to after the drug was administered were investigated within each group using the Wilcoxon signed-rank tests or paired $t$ test. Significance was accepted as $\mathrm{p}<0.05$.

\section{RESULTS}

Table 1 summarises the baseline characteristics of the study group, which were similar between the groups. Importantly, the time from symptom onset to reperfusion and peak CK-MB were similar between the two groups. Furthermore, baseline LVEF, blood pressure and LV volumes were all similar between the two groups at baseline. An ACEI was started between 12 and $24 \mathrm{~h}$ and $\beta$-blocker therapy was started within $12 \mathrm{~h}$ in all patients in both groups. At the end of the $72 \mathrm{~h}$ infusion period all patients in both groups were receiving an ACEI; in the 0.003 group, $100 \%$ of patients were receiving lisinopril (mean dose $12 \mathrm{mg} /$ day), while in the 0.006 group, $80 \%$ were receiving lisinopril (mean dose $5 \mathrm{mg} /$ day) and $20 \%$ captopril (mean dose $37.5 \mathrm{mg} /$ day). At 1-month follow-up, all patients in both groups were still receiving an ACEI or angiotensin receptor blocker (ARB); in the 0.003 group, $100 \%$ of patients were receiving lisinopril (mean dose $8 \mathrm{mg} /$ day), while in the 0.006 group, $80 \%$ were receiving lisinopril (mean dose $6 \mathrm{mg} /$ day), $10 \%$ captopril (mean dose $18.75 \mathrm{mg} /$ day) and $10 \%$ irbesartan (mean dose $150 \mathrm{mg} /$ day). For $\beta$-blocker therapy, at the end of the $72 \mathrm{~h}$ infusion period all patients in both groups were receiving a $\beta$ blocker; in the 0.003 group, $73 \%$ of patients were receiving metoprolol (mean dose $120 \mathrm{mg} /$ day), 18\% atenolol (mean dose $37.5 \mathrm{mg} /$ day) and 9\% Toprol XL (mean dose $25 \mathrm{mg} /$ day), while in the 0.006 group, $90 \%$ were receiving metoprolol (mean dose $80 \mathrm{mg} /$ day) and 10\% atenolol (mean dose $25 \mathrm{mg} /$ day). At the 1-month follow-up all patients in both groups were receiving a $\beta$ blocker except for one patient in the 0.006 group; in the 0.003 group, $73 \%$ of patients were receiving metoprolol (mean dose $117 \mathrm{mg} /$ day), 18\% atenolol (mean dose $37.5 \mathrm{mg} /$ day) and 9\% Toprol XL (mean dose $25 \mathrm{mg} /$ day), while in the 0.006 group, $90 \%$ were receiving metoprolol (mean dose $75 \mathrm{mg} /$ day), 10\% atenolol (mean dose $25 \mathrm{mg} /$ day) and 10\% (one patient) had stopped the $\beta$

Table 1 Patient baseline characteristics

\begin{tabular}{|c|c|c|c|}
\hline Characteristics & $\begin{array}{l}0.003 \text { group } \\
(n=12)\end{array}$ & $\begin{array}{l}0.006 \text { group } \\
(n=12)\end{array}$ & p Value \\
\hline Age (years) & $59(3)$ & $58(4)$ & 0.772 \\
\hline Male, n (\%) & $9(75)$ & $6(50)$ & 0.400 \\
\hline Body mass index $\left(\mathrm{kg} / \mathrm{m}^{2}\right)$ & $30(1)$ & $34(2)$ & 0.260 \\
\hline Body surface area $\left(\mathrm{m}^{2}\right)$ & $2(0.1)$ & $2(0.1)$ & 0.954 \\
\hline PTCA/thrombolytic agents & $12: 0$ & 11:1 & 1.000 \\
\hline Hypertension, n (\%) & $5(42)$ & $6(50)$ & 1.000 \\
\hline Diabetes, n (\%) & $3(25)$ & $0(0)$ & 0.214 \\
\hline Time to reperfusion (min) & $321(72)$ & $253(75)$ & 0.214 \\
\hline Creatine kinase-MB peak (ng/ml) & $217(80)$ & $212(50)$ & 0.926 \\
\hline Systolic blood pressure (mm Hg) & $127(5)$ & $125(8)$ & 0.544 \\
\hline Diastolic blood pressure $(\mathrm{mm} \mathrm{Hg})$ & $76(4)$ & $78(6)$ & 0.707 \\
\hline LV ejection fraction (\%) & $42(2)(n=11)$ & $40(4)(n=10)$ & 0.972 \\
\hline LV end-systolic volume $\left(\mathrm{ml} / \mathrm{m}^{2}\right)$ & $60(11)(n=10)$ & $61(9)(n=9)$ & 1.000 \\
\hline LV end-diastolic volume $\left(\mathrm{ml} / \mathrm{m}^{2}\right)$ & $104(18)(n=10)$ & $96(11)(n=9)$ & 0.939 \\
\hline ACEI or ARB, $n(\%)$ & $1(8)$ & $2(17)$ & 1.000 \\
\hline$\beta$ Blocker, $\mathrm{n}(\%)$ & $3(25)$ & $2(17)$ & 1.000 \\
\hline
\end{tabular}

Results are shown as mean (SEM) unless stated otherwise.

$\mathrm{ACEl}$, angiotensin converting enzyme inhibitor; $A R B$, angiotensin receptor blocker; LV, left ventricular; PTCA, percutaneous transluminal coronary angioplasty.
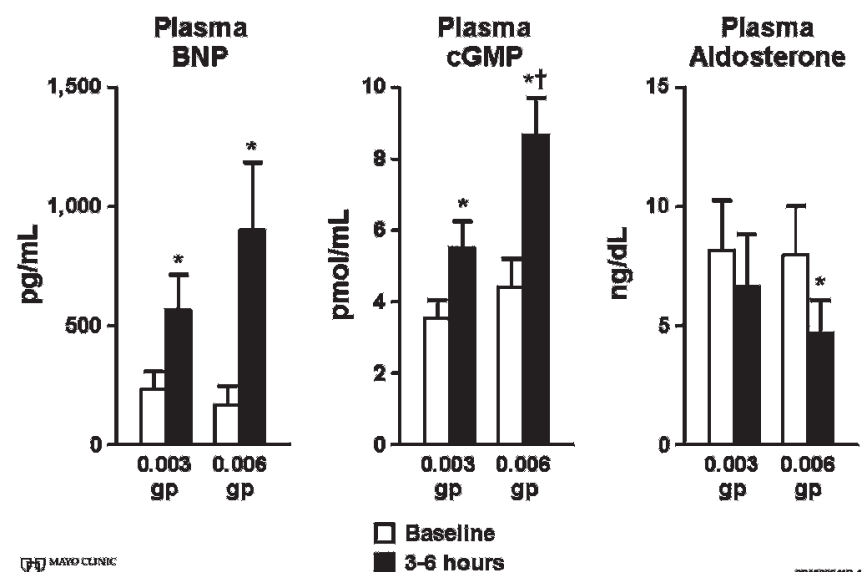

Figure 1 Plasma B-type natriuretic peptide (BNP), cyclic 3', 5'guanosine monophosphate (cGMP) and aldosterone at baseline and between 3 and $6 \mathrm{~h}$ after the start of the BNP infusion. ${ }^{*} \mathrm{p}<0.05$ versus baseline; $\uparrow \mathrm{p}<0.05$ for change from baseline versus 0.003 group.

blocker. None of the patients received an aldosterone antagonist at the end of the $72 \mathrm{~h}$ infusion period or at 1 month.

Figure 1 shows that after 3-6 h of infusion, plasma BNP increased from baseline in a dose-dependent fashion. Plasma cGMP, the second messenger of BNP, which is also a marker of the biological actions of BNP, increased marginally in the 0.003 group and a much greater increase was seen in the 0.006 group. This cGMP response in the plasma supports the conclusion that the $0.006 \mu \mathrm{g} / \mathrm{kg} / \mathrm{min}$ dose is more biologically active than the $0.003 \mu \mathrm{g} / \mathrm{kg} / \mathrm{min}$ dose. Consistent with the greater biological activity of the $0.006 \mu \mathrm{g} / \mathrm{kg} / \mathrm{min}$ dose was the observation that plasma aldosterone was significantly reduced in the 0.006 group while there was only a trend for it to decrease in the 0.003 group.

Figures 2 and 3 show that LVEF was significantly higher while LV end-systolic volume was significantly reduced at 4 weeks as compared with baseline in the 0.006 group. The individual plot graph (fig 2, right) shows that every patient in the 0.006 group had an improvement of LVEF at 4 weeks as compared with baseline. In contrast, in the 0.003 group, there was only a non-significant trend for LVEF to improve and LV end-systolic volume to decrease at 4 weeks as compared with baseline. The increase in LVEF at 4 weeks was significantly

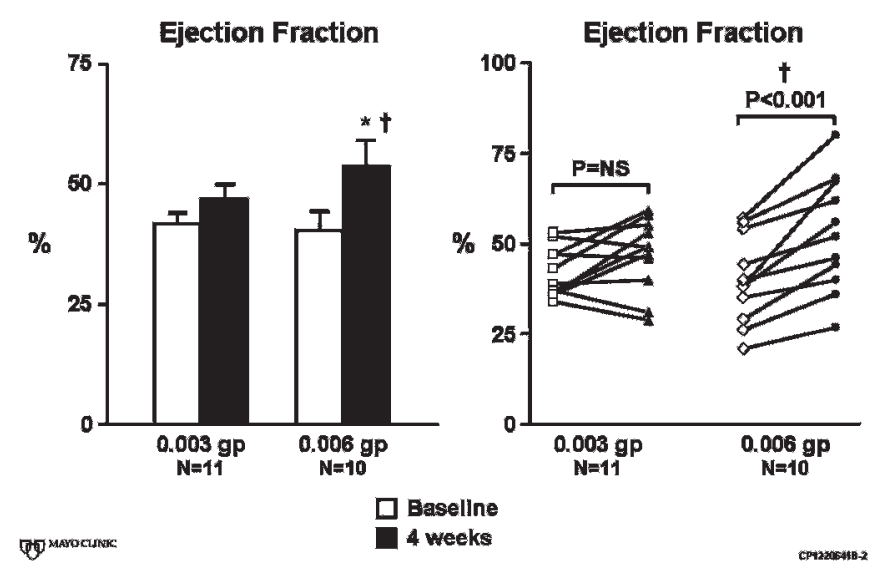

Figure 2 Left ventricular ejection fraction represented as bar graph and individual plot at baseline and 4 weeks. ${ }^{*} p<0.05$ versus baseline; $\dagger p<0.05$ for change from baseline versus 0.003 group. 


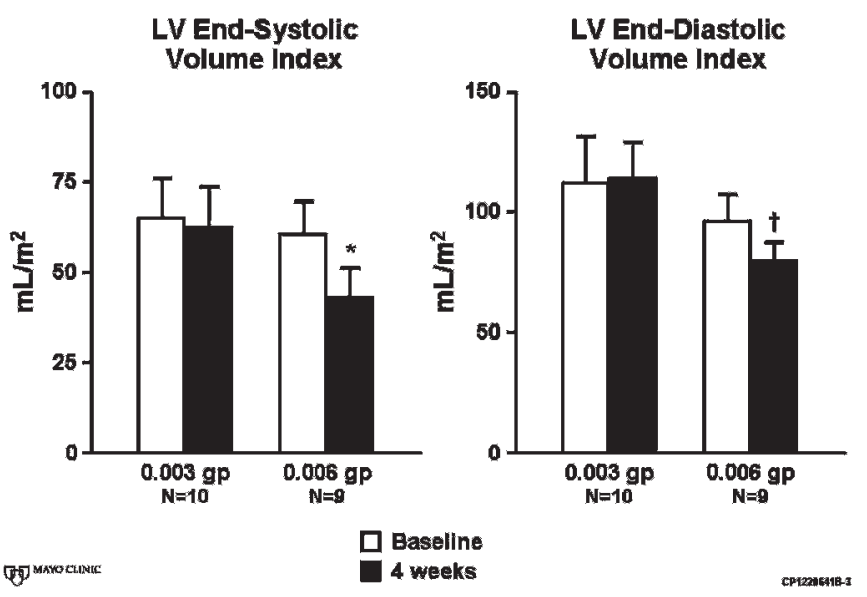

Figure 3 Left ventricular (LV) end-systolic volume index and LV enddiastolic volume index at baseline and 4 weeks. ${ }^{*} \mathrm{p}<0.05$ versus baseline; $\uparrow \mathrm{p}<0.05$ versus 0.003 group.

greater in the 0.006 group than in the 0.003 group. There was a strong trend $(p=0.09)$ for the reduction in LV end-systolic volume at 4 weeks to be greater in the 0.006 group than in the 0.003 group. Lastly, at 4 weeks, LV end-diastolic volume was significantly smaller in the 0.006 group than in the 0.003 group.

\section{Safety}

\section{Blood pressure}

Two patients in the 0.003 group and two in the 0.006 group had the infusion of BNP discontinued for symptomatic hypotension which resolved with no clinical consequences after the infusion was stopped. The lowest systolic and diastolic blood pressures during the $72 \mathrm{~h}$ infusion period were similar between the two groups (0.003 group: 93/54 (4/4) mm Hg; 0.006 group: 85/50 (3/ 3) $\mathrm{mm}, \mathrm{Hg} \mathrm{p}=\mathrm{NS}$ ). To enable us to determine how these changes in blood pressure with BNP compared with standard care, we retrospectively collected data on systolic and diastolic blood pressures in 15 age- and sex-matched historical controls admitted to the coronary care unit for acute anterior AMI. The baseline blood pressure in the historic control group was 119/71 $(4 / 3) \mathrm{mm} \mathrm{Hg}$ and the lowest blood pressure during the first $72 \mathrm{~h}$ in the coronary care unit was $86 / 4(4 / 3) \mathrm{mm} \mathrm{Hg}$.

\section{Renal function}

Plasma creatinine and blood urea nitrogen were similar between the two groups and remained unchanged after the BNP infusion at $72 \mathrm{~h}$ (table 2).

There were no drug-related serious adverse events in either group.

Table 2 Plasma creatinine and blood urea nitrogen

\begin{tabular}{lccc}
\hline & Baseline & At $\mathbf{7 2} \mathbf{~ h}$ & p Value \\
\hline 0.003 group $(n=11)$ & & & \\
Plasma creatinine $(\mathrm{mg} / \mathrm{dll})$ & $1.1(0.1)$ & $1.1(0.1)$ & 0.900 \\
Plasma BUN (mg/dl) & $20(1)$ & $18(2)$ & 0.200 \\
& & & \\
0.006 group $(n=12)$ & $1.1(0.1)$ & $1.1(0.1)$ & 0.500 \\
Plasma creatinine (mg/dl) & $19(3)$ & $18(2)$ & 0.500 \\
Plasma BUN (mg/dl) & & & \\
\hline
\end{tabular}

Results are shown as mean (SEM).

BUN, blood urea nitrogen.

\section{DISCUSSION}

In this proof-of-concept pilot human study in human anterior AMI, $72 \mathrm{~h}$ of intravenous infusion of recombinant BNP activated plasma cGMP and suppressed plasma aldosterone during the infusion period with reduction of cardiac dilatation and an improvement in ejection fraction 1 month after infusion in comparison with baseline. These findings in human AMI provides support for the potential efficacy of BNP therapy in patients with ST elevation anterior AMI to prevent adverse LV remodelling and improve LV function, which is now being tested in a double-blind, placebo-controlled, NIH-supported clinical trial.

Human AMI, whose incidence in the United States is unchanged, is a major contributor to the development of HF and death. Our study examines the concept of preservation of cardiac function and structure at the time of AMI in humans employing the cardiac peptide BNP as new protein therapy for myocardial protection. The need to protect the heart from excessive hypertrophy, fibrosis, dilatation and loss of contractile function is a high priority that has resulted in extensive research to develop new therapeutic strategies for AMI. Antagonism of the fibrosis-inducing steroid hormone aldosterone proved to be efficacious after AMI when HF was present. ${ }^{17}$ Cell therapy especially in humans has followed a similar paradigm that employs intracardiac delivery after AMI. ${ }^{18}$ We used a different tactic that used a synthesised endogenous cardiac peptide, BNP, to enhance cardiac structure and function in human AMI based on its pleiotropic properties for cardiac protection and repair.

One study reported that capillary density was enhanced in a murine model of peripheral limb ischaemia in BNP transgenic mice. ${ }^{5}$ These studies of BNP and vascular regeneration via cGMP provide additional insight into possible mechanisms promoting myocardial survival and repair in AMI. In addition, studies in a rodent model of AMI, in which BNP administration attenuated infarct size, which was independent of myocardial unloading actions, implicated BNP activation of cGMP and opening of ATP sensitive potassium ( $\mathrm{K}_{\mathrm{ATP}}$ ) channels; this may involve an additional protective mechanism as has been demonstrated in cGMP-mediated protection in the setting of hibernating myocardium. ${ }^{19}$ Supporting such a mechanism is the report by the J-WIND investigators that patients with AMI who were given ANP had lower infarct size, fewer reperfusion injuries and better outcomes than controls. " Additional mechanisms of the cardioprotection afforded by BNP and the NPR-A/cGMP receptor complex may include coronary vasodilating, myocardial relaxing and anti-hypertrophic properties. ${ }^{320}$ Indeed, this is further complemented by direct actions on cardiac fibroblasts to suppress collagen synthesis and cell proliferation. ${ }^{6}$ While all these mechanisms may be operative, we observed in this study that there was suppression of aldosterone with the $0.006 \mu \mathrm{g} / \mathrm{kg} /$ min dose of BNP. This suppression of aldosterone is a unique property of the natriuretic peptides and given the various deleterious properties of aldosterone such inhibition may be important in the favourable actions of BNP in AMI.

Our study demonstrates that the cardiac hormone BNP can be delivered easily, and is generally well tolerated, within $24 \mathrm{~h}$ of onset of AMI. Although symptomatic hypotension occurred in two patients in each group, it resolved quickly without adverse consequences after discontinuation of the study drug. When our results are compared with historical control data for reductions in blood pressure with standard treatment, we conclude that the reduction in blood pressure during BNP infusion may not have been due to BNP. At these low doses, there were no detrimental effects in renal function, on the 
contrary, there was a very slight trend for blood urea nitrogen to improve at $72 \mathrm{~h}$ as compared with baseline in both groups.

In this study BNP therapy for $72 \mathrm{~h}$ improved myocardial structure 1 month after AMI compared with baseline. As far as we know, this study is the first to report the potential antiremodelling action of BNP in the setting of anterior AMI after successful revascularisation, and complements the recent report by Hillock et al in which 28 patients with AMI with delayed or failed reperfusion and moderate left ventricular dysfunction were randomised to receive an infusion of BNP at $0.01 \mu \mathrm{g} / \mathrm{kg} /$ min or placebo for $60 \mathrm{~h}$ after MI. The investigators concluded that the trends in left ventricular remodelling in the patients receiving nesiritide were favourable. ${ }^{10}$ Previous studies by Hayashi et al and Kasama et al demonstrated that infusion of ANP after successful revascularisation for anterior AMI also prevented adverse LV remodelling. ${ }^{13} 21$ It should be noted, however, that in the Hayashi study, an ACEI was withheld until the $72 \mathrm{~h}$ infusion was completed, and in the Kasama study, it was unclear when the ACEI was started. In our study, an ACEI was administered between 12 and $24 \mathrm{~h}$ after the start of the infusion. Thus, this study followed clinical practice guidelines specified by the American Heart Association/ American College of Cardiology requiring use of an ACEI within $24 \mathrm{~h}$ of anterior AMI. ${ }^{22}$ The fact that we were able to demonstrate cardioprotection even in the presence of early ACEI therapy underlines the potent anti-remodelling action of $\mathrm{BNP}$ in the setting of anterior AMI.

\section{Limitations}

This study was designed as a translational proof-of-concept investigation of the use of low-dose BNP to demonstrate safety and cardioprotection in human first time AMI not as a definitive clinical trial as the number of patients was small and there was no placebo group. Nonetheless, the findings reported here provided the rationale for the successful funding and launching of the NIH-supported, double-blind, randomised trial now underway.

In conclusion, this proof-of-concept study demonstrates that a $72 \mathrm{~h}$ infusion of low-dose recombinant BNP at the time of anterior AMI is well tolerated and is biologically active as shown by the increase in plasma cGMP and reduction in plasma aldosterone. Specifically, patients treated with BNP at this cGMP-activating dose had improved LVEF and smaller LV endsystolic volume at 1 month. Based on these findings, more definitive clinical trials are warranted, which may lead to a safe, efficacious and widely available clinical strategy that ultimately may reduce the burden of heart failure.

Funding: This work was supported by research grants from Scios Inc and the Mayo Foundation.

Competing interests: $\mathrm{HHC}, \mathrm{MMR}$ and JCB have received research grant from Scios Inc and the Mayo Clinic. JCB, RDS and HHC have patented and received royalties for designer natriuretic peptides. HHC has received royalties from Uptodate Inc. Mayo Clinic has patented and licensed designer natriuretic peptides.

Ethics approval: Ethics committee approval from the Mayo Clinic Institutional Review Board.

\section{REFERENCES}

1. Holtwick R, van Eickels M, Skryabin BV, et al. Pressure-independent cardiac hypertrophy in mice with cardiomyocyte-restricted inactivation of the atrial natriuretic peptide receptor guanylyl cyclase-A. J Clin Invest 2003;111:1399-407.

2. Michaels AD, Klein A, Madden JA, et al. Effects of intravenous nesiritide on human coronary vasomotor regulation and myocardial oxygen uptake. Circulation 2003;107:2697-701.

3. Lainchbury JG, Burnett JC Jr, Meyer D, et al. Effects of natriuretic peptides on load and myocardial function in normal and heart failure dogs. Am J Physiol Heart Circ Physiol 2000;278:H33-40.

4. Brunner-La Rocca HP, Kaye DM, Woods RL, et al. Effects of intravenous brain natriuretic peptide on regional sympathetic activity in patients with chronic heart failure as compared with healthy control subjects. J Am Coll Cardiol 2001;37:1221-7.

5. Yamahara K, Itoh $\mathrm{H}$, Chun $\mathrm{TH}$, et al. Significance and therapeutic potential of the natriuretic peptides/cGMP/cGMP-dependent protein kinase pathway in vascular regeneration. Proc Natl Acad Sci USA 2003;100:3404-9.

6. Kapoun AM, Liang F, O'Young G, et al. B-type natriuretic peptide exerts broad functional opposition to transforming growth factor-beta in primary human cardiac fibroblasts: fibrosis, myofibroblast conversion, proliferation, and inflammation. Circ Res 2004;94:453-61.

7. Tsuruda T, Boerrigter G, Huntley BK, et al. Brain natriuretic peptide is produced in cardiac fibroblasts and induces matrix metalloproteinases. Circ Res 2002;91:1127-34.

8. Kato T, Muraski J, Chen Y, et al. Atrial natriuretic peptide promotes cardiomyocyte survival by cGMP-dependent nuclear accumulation of zyxin and Akt. J Clin Invest 2005:115:2716-30.

9. Kitakaze M, Asakura M, Kim J, et al. Human atrial natriuretic peptide and nicorandil as adjuncts to reperfusion treatment for acute myocardial infarction (J-WIND): two randomised trials. Lancet 2007;370:1483-93.

10. Hillock RJ, Frampton CM, Yandle TG, et al. B-type natriuretic peptide infusions in acute myocardial infarction. Heart 2008;94:617-22.

11. Chen HH, Sundt TM, Cook DJ, et al. Low dose nesiritide and the preservation of renal function in patients with renal dysfunction undergoing cardiopulmonary-bypass surgery: a double-blind placebo-controlled pilot study. Circulation 2007;116(Suppl):I134-8

12. Riter H, Redfield MM, Burnett JC, et al. Non-hypotensive low dose nesiritide has differential renal effects compared to standard dose nesiritide in patients with acute decompensated heart failure and renal dysfunction. J Am Coll Cardiol 2006:47:2334-5.

13. Hayashi M, Tsutamoto T, Wada A, et al. Intravenous atrial natriuretic peptide prevents left ventricular remodeling in patients with first anterior acute myocardial infarction. J Am Coll Cardiol 2001;37:1820-6.

14. Dargie HJ. Effect of carvedilol on outcome after myocardial infarction in patients with left-ventricular dysfunction: the CAPRICORN randomised trial. Lancet 2001;357:1385-90.

15. Clements IP, Brown ML, Smith HC. Radionuclide measurement of left ventricular volume. Mayo Clin Proc 1981;56:733-9.

16. Cataliotti A, Boerrigter G, Costello-Boerrigter LC, et al. Brain natriuretic peptide enhances renal actions of furosemide and suppresses furosemide-induced aldosterone activation in experimental heart failure. Circulation 2004;109:1680-5.

17. Pitt B, Remme W, Zannad F, et al. Eplerenone, a selective aldosterone blocker, in patients with left ventricular dysfunction after myocardial infarction. N Engl J Med 2003;348:1309-21.

18. Assmus B, Schachinger V, Teupe C, et al. Transplantation of Progenitor Cells and Regeneration Enhancement in Acute Myocardial Infarction (TOPCARE-AMI). Circulation 2002;106:3009-17.

19. D'Souza SP, Yellon DM, Martin C, et al. B-type natriuretic peptide limits infarct size in rat isolated hearts via KATP channel opening. Am J Physiol Heart Circ Physiol 2003;284:H1592-600.

20. Franco V, Chen YF, Oparil S, et al. Atrial natriuretic peptide dose-dependently inhibits pressure overload-induced cardiac remodeling. Hypertension 2004;44:746-50.

21. Kasama S, Toyama T, Hatori $T$, et al. Effects of intravenous atrial natriuretic peptide on cardiac sympathetic nerve activity and left ventricular remodeling in patients with first anterior acute myocardial infarction. J Am Coll Cardiol 2007;49:667-74.

22. Antman EM, Anbe DT, Armstrong PW, et al. ACC/AHA guidelines for the management of patients with ST-elevation myocardial infarction-executive summary: a report of the American College of Cardiology/American Heart Association Task Force on Practice Guidelines (Writing Committee to Revise the 1999 Guidelines for the Management of Patients With Acute Myocardial Infarction). Circulation 2004;110:588-636. 